\title{
Communication \\ Potential Use of Carrageenans against the Limestone Proliferation of the Cyanobacterium Parakomarekiella sesnandensis
}

\author{
Fabiana Soares ${ }^{1, *}$, João Trovão ${ }^{1}$, Francisco Gil ${ }^{2} \mathbb{D}$, Lídia Catarino ${ }^{3} \mathbb{D}$, Igor Tiago ${ }^{1} \mathbb{D}$, António Portugal ${ }^{1,4}(\mathbb{D}$ \\ and Susana M. Cardoso ${ }^{5}$ (D)
}

1 Centre for Functional Ecology, Department of Life Sciences, University of Coimbra, 3000-456 Coimbra, Portugal; jtrovaosb@gmail.com (J.T.); itiago@uc.pt (I.T.); aportuga@bot.uc.pt (A.P.)

2 Center for Physics, Department of Physics, University of Coimbra, 3004-516 Coimbra, Portugal; fgil@fis.uc.pt

3 Geosciences Center, Department of Earth Sciences, University of Coimbra, 3030-790 Coimbra, Portugal; lidiagil@dct.uc.pt

4 Fitolab-Laboratory for Phytopathology, Instituto Pedro Nunes, 3030-199 Coimbra, Portugal

5 LAQV-REQUIMTE, Department of Chemistry, University of Aveiro, 3810-193 Aveiro, Portugal; susanacardoso@ua.pt

* Correspondence: fabiana.alm.soares@gmail.com

Citation: Soares, F.; Trovão, J.; Gil, F.; Catarino, L.; Tiago, I.; Portugal, A.;

Cardoso, S.M. Potential Use of

Carrageenans against the Limestone Proliferation of the Cyanobacterium Parakomarekiella sesnandensis. Appl. Sci. 2021, 11, 10589. https://doi.org/ 10.3390/app112210589

Academic Editor: Filomena De Leo

Received: 15 October 2021

Accepted: 8 November 2021

Published: 10 November 2021

Publisher's Note: MDPI stays neutral with regard to jurisdictional claims in published maps and institutional affiliations.

Copyright: (c) 2021 by the authors. Licensee MDPI, Basel, Switzerland. This article is an open access article distributed under the terms and conditions of the Creative Commons Attribution (CC BY) license (https:/ / creativecommons.org/licenses/by/ $4.0 /)$.

\begin{abstract}
Stone biodeterioration by cyanobacteria is a common issue in the field of cultural heritage. As they are considered the first stone colonizers, the need to control their growth has increased. In this study, we evaluated the effectiveness of kappa/iota carrageenans from the red seaweed Chondracanthus teedei var. lusitanicus against the limestone proliferation of the cyanobacterium Parakomarekiella sesnandensis, under laboratory conditions. For this purpose, $200 \mu \mathrm{L}$ of kappa/iota carrageenans $\left(0.01 \mathrm{~g} \mathrm{~mL}^{-1}\right)$ were applied into the surface of the limestone replicas prior to their inoculation with P. sesnandensis. Results were evaluated after 4 months of incubation through visual inspection, stereomicroscopy, scanning electron microscopy and colorimetric analyses. The gathered data demonstrated that these types of carrageenans have the potential to reduce the colonization of $P$. sesnandensis. With one sole application, the aesthetical alterations caused by the proliferation of $P$. sesnandensis were drastically reduced. This study highlights the need to explore marine-based products, particularly those derived from seaweeds with antimicrobial properties, as alternative methods for biocleaning cultural heritage assets.
\end{abstract}

Keywords: biodeterioration; carrageenans; cyanobacteria; limestone; natural compounds; seaweeds

\section{Introduction}

Microalgae and cyanobacteria are photosynthetic organisms capable of colonizing aquatic, as well as a variety of terrestrial habitats, including barks of trees, soils and stone substrates [1]. In regard to stone monuments, they are considered the primary colonizers, and their proliferation on such materials often results in severe aesthetical and physicochemical damage [2-4]. Cyanobacteria in particular are known to be capable of weakening the minerals of the stone substrates and to cause biomineralization, leading to stone deterioration $[5,6]$.

As stone monuments can provide protected shelter for microorganisms [7], they can also be the source of novel taxa with an unknown biodeterioration role. This is the case of the recently described cyanobacterium Parakomarekiella sesnandensis, which has been previously found in the limestone walls of the Old Cathedral of Coimbra [8,9]. The new strain, described by Soares and colleagues [9], is a member of the family Nostocaceae and was characterized based on morphological, molecular, phylogenetic and ecological data. The isolation and characterization of taxa from stone monuments represent the first step towards monument preservation and conservation. In this regard, to avoid the 
proliferation of harmful microorganisms on stone monuments, control and prevention procedures are often employed with the ultimate goal of accomplishing a good state of conservation. However, the majority of these procedures often involve the use of chemicals (biocides) that might cause even more damage to the substrata and/or do not produce long-lasting results, in addition to their potential negative impact in terms of environment and human health [10-12]. For this reason, there is an increased interest in the use of more eco-friendly, long-lasting and cost-effective treatments based on natural products derived from microorganisms and plants $[11,12]$. Some recent studies have already demonstrated the use of natural compounds against colonization of stone monuments by phototrophic microorganisms in the field of cultural heritage $[11,13,14]$. Nevertheless, as progress with the use of natural compounds as biocide treatments has been made, to the best of our knowledge, there are still a variety of products, particularly marine-derived compounds, largely unexplored in cultural heritage studies.

Carrageenans are sulfated polysaccharides that are found in the cell walls of red seaweeds [15] and are known to possess a variety of biological properties, including antioxidant, anti-inflammatory, antiviral, antibacterial and antifungal activities [16-18]. Chemically, these polysaccharides are composed of galactose and possess a high content of sulfate esters [19], albeit distinct variations usually occur. In fact, carrageenans are normally classified based on distinct features, including the number and position of sulfate groups, the presence of presence of 3,6-anhydro-D-galactose and the conformation of the pyranose ring [20]. The most common types of carrageenans are $k$ (kappa), $\mathrm{l}$ (iota) and $\lambda$ (lambda): kappa-carrageenans have alternating (1-3)- $\beta$-D-galactose-4-sulfate and (1-4)-3,6-anhydro- $\alpha$-D-galactose units, while iota-carrageenans have an additional sulfate group on C-2(O) of the (1-4)-3,6-anhydro- $\alpha$-D-galactose sugars, resulting in two sulfates per disaccharide repeating unit [21]. On the other hand, lambda-carrageenans have an additional sulfate group linked to the C-6 position of the 4-linked residue, but in turn this is a (1-4)- $\alpha$-D-galactopyranose. Regardless of the abundancy of these structures, instead of producing pure carrageenans, seaweeds may produce hybrid structures such as $v(\mathrm{nu})$, $\mu(\mathrm{mu}), \theta$ (theta), $\beta$ (beta) and $\xi$ (xi). The biological precursors $\mathrm{mu}$ and nu, upon alkali treatment, are modified into kappa and iota carrageenans, respectively, through formation of the 3,6-anhydro-galactose bridge [22,23].

Chondracanthus teedei var. lusitanicus is a red seaweed from the family Gigartinaceae and presents a triphasic isomorphic life cycle [24-27]. Its geographical distribution is limited to the Iberian Peninsula, being found in several localities on the Portuguese coast and on the northwest coast of Spain [28-30]. Previous studies performing FTIR-ATR and FT-Raman analysis revealed that $C$. teedei var. lusitanicus is known to produce different carrageenan types according to its life cycle phase - the tetrasporophyte phase produces lambda family carrageenans (hybrid xi/theta) and the gametophyte phases produce hybrid kappa/iota carrageenans $[18,28,31]$. Although both types of carrageenans from C. teedei var. lusitanicus have shown antifungal activity and a slight antiviral activity [18,32], to the best of our knowledge, carrageenans have never been tested in cultural heritage studies. Therefore, the aim of this study was to evaluate the effectiveness of carrageenans extracted from the female gametophyte life cycle phase of $C$. teedei var. lusitanicus against the limestone proliferation of the cyanobacterium Parakomarekiella sesnandensis, under laboratory conditions.

\section{Materials and Methods}

\subsection{Cultivation of the Cyanobacterium Strain}

The strain used in this study, P. sesnandensis, has been previously collected from two green biofilms from the limestone walls of the Old Cathedral of Coimbra [8]. The strain was isolated from enrichment cultures by means of micromanipulation using an inverted microscope and has been kept incubated in liquid $\mathrm{BG}_{11}$ culture medium in laboratory at $20 \pm 1{ }^{\circ} \mathrm{C}$, under a 16:8 $\mathrm{h}$ (light:dark) photoperiod (30-40 $\mu$ mol photons $\mathrm{m}^{-2} \mathrm{~s}^{-1}$ irradiance). 


\subsection{Preparation of Carrageenans Extract}

\subsubsection{Harvesting of Seaweed Material}

Specimens of C. teedei var. lusitanicus were collected from Buarcos Bay, Portugal $\left(40^{\circ} 16^{\prime} \mathrm{N}, 8^{\circ} 90^{\prime} \mathrm{W}\right)$ and washed in situ to remove sand and salts. At the laboratory, samples were rinsed with autoclaved distilled water and were properly cleaned to remove debris and epiphytes (if any). Samples from the female gametophyte life cycle (identified with a magnifying glass and based on the presence of prominent spherical cystocarps) were separated and used for extraction of carrageenans. This life cycle phase was selected since preliminary studies using the tetrasporophyte life cycle phase did not show any positive results (data not shown).

\subsubsection{Carrageenans Extraction}

The previously separated and cleaned samples were dried at $60{ }^{\circ} \mathrm{C}$ and grounded for further treatment. Carrageenans were obtained by an alkali extraction and, for this, $1 \mathrm{~g}$ of the ground dried material was pretreated with a mixture of 1:1 acetone and methanol, for $12 \mathrm{~h}$, to eliminate the organo-soluble fraction [33]. The material was then placed in $150 \mathrm{~mL}$ of $\mathrm{NaOH}(1 \mathrm{M})$, in a hot bath for $3 \mathrm{~h}$, at $85-90{ }^{\circ} \mathrm{C}$ [28]. The solution was then filtered twice using a cloth filter, under vacuum, and while still hot. Carrageenans precipitated by adding to the hot filtered solution twice its volume of $96 \%$ ethanol. This resulted in the formation of a whitish clog, which was dried at $50-60{ }^{\circ} \mathrm{C}$, for $24 \mathrm{~h}$ [28]. The obtained extract was then grounded, and stock solutions of $0.01 \mathrm{~g} \mathrm{~mL}^{-1}$ were prepared with autoclaved distilled water and stored at $-20{ }^{\circ} \mathrm{C}$ until further use.

\subsection{Laboratory-Based Application of Carrageenans on Dolomitic Limestone Replicas}

For the application of carrageenans, dolomitic limestone replicas $(4 \mathrm{~cm} \times 4 \mathrm{~cm} \times 3 \mathrm{~cm})$ with a similar composition to the limestones found in the walls of the Old Cathedral of Coimbra were used. Before application of carrageenans, stone replicas were washed with sterile water, autoclaved at $120^{\circ} \mathrm{C}$ and $1 \mathrm{~atm}$ for $20 \mathrm{~min}$ and left for cooling. After this, a volume of $200 \mu \mathrm{L}$ of the stock solution of the carrageenans was applied and spread into the surface of each stone probe. After drying, each stone replica containing the carrageenans was inoculated with a volume of $200 \mu \mathrm{L}$ of $P$. sesnandensis and placed inside a propylene box with sterile water at the bottom, to create a humid environment. The propylene boxes were then incubated at $20 \pm 1{ }^{\circ} \mathrm{C}$, under a 16:8 h (light:dark) photoperiod (30-40 $\mu \mathrm{mol}$ photons $\mathrm{m}^{-2} \mathrm{~s}^{-1}$ irradiance) for 4 months. Control replicas consisted of stones inoculated with $P$. sesnandensis in the absence of carrageenans. A control consisting of stone replicas with carrageenans in the absence of cyanobacterium was also prepared, in order to evaluate any negative effect (i.e., change of color) resulting from the application of the treatment. All replicas were incubated under the same conditions described above and all experiments were conducted in triplicate.

Complementarily, we performed control replicas of stone with and without treatment outside of the humid environment (herein designated as non-experimental), in order to understand if there were differences in the stone color upon application of the carrageenans under humid (experimental) vs. dry environment (non-experimental).

\subsection{Evaluation of Carrageenans Treatment on the Proliferation of P. sesnandensis on Stone Replicas}

To evaluate the effectiveness of the carrageenan treatment, the occupied area $\left(\mathrm{cm}^{2}\right)$ colonized by $P$. sesnandensis on each stone probe was assessed and photographed using a light microscope, after 4 months of the carrageenans application. The area of colonization was measured using ImageJ software. Complementarily, scanning electron microscopy (SEM) and colorimetric analyses were also performed, in order to assess P. sesnandensis proliferation and color variations on stone probes, respectively.

For SEM analysis, samples were prepared by scraping off biomass growing on the surface of the stone replicas with and without treatment and by letting them dry for $24 \mathrm{~h}$ before 
proceeding with the application of a gold/palladium ( $\mathrm{Au} / \mathrm{Pd}$ ) coating using an SC7620 Mini Sputter Coater/Glow Discharge System, following the manufacturer's protocol. Analyses were conducted using a TESCAN Vega3 SBH (TESCAN, Brno, Czech Republic).

Colorimetric analyses were conducted with a portable spectrophotometer CM-700d (Konica Minolta, Japan) with a $3 \mathrm{~mm}$ measuring aperture. Readings were performed directly on the surface of each stone replica with and without the carrageenans treatment. CIELAB method was applied in order to quantify the color of the stone surface by three parameters: $\mathrm{L}^{*}$ (light/darkness), $\mathrm{a}^{*}$ (red-green) and $\mathrm{b}^{*}$ (yellow-blue). Total color variation $\left(\Delta \mathrm{E}^{*}\right)$ was obtained by using the CIE formula: $\Delta \mathrm{E}^{*} \mathrm{ab}=\left[\left(\Delta \mathrm{L}^{*}\right) 2+\left(\Delta \mathrm{a}^{*}\right) 2+\left(\Delta \mathrm{b}^{*}\right) 2\right] 1 / 2[34,35]$. For this analysis, and in order to assess if humid and dried conditions altered the studied $\Delta \mathrm{E}^{*}$ values, two additional stone probe controls were taken into account. For this, one stone probe was incubated outside the propylene boxes (dry condition) without carrageenan treatment and without the presence of the cyanobacterium P. sesnandensis (here designated as stone control non-experimental); the other stone probe was also incubated in a dry environment, but this time with carrageenan treatment and without $P$. sesnandensis (designated as biocide on stone control non-experimental).

\subsection{Statistical Analysis}

Statistical analysis was performed in order to evaluate the differences in the stone colonization/proliferation area $\left(\mathrm{cm}^{2}\right)$ by P. sesnandensis in the presence and in the absence of carrageenan extracts. The analysis was conducted by using an unpaired $t$ test in GraphPad Prism 8.1 (San Diego, CA, USA, www.graphpad.com, last accessed on 2 November 2021).

\section{Results}

\subsection{Effect of Carrageenans on the Proliferation of P. sesnandensis}

The results obtained in this study demonstrated that, with just one application of $200 \mu \mathrm{L}$ of kappa/iota hybrid carrageenans solution $\left(0.01 \mathrm{~g} \mathrm{~mL}^{-1}\right)$, the proliferation area of P. sesnandensis on stone replicas was drastically reduced, compared to non-treated stones (Figure 1). Visual examination demonstrated that in the non-treated stone replicas (Figure 1a,b), P. sesnandensis was able to colonize a more extensive area than in stone replicas submitted to carrageenans treatment (Figure 1c,d). Results from statistical analysis demonstrated that these differences were statistically significant (Table 1). Stereo microscopic analysis also showed that, when treatment was applied, cells of $P$. sesnandensis started to become less green and turned yellow (Figure $1 \mathrm{~g}, \mathrm{~h}$ ), in contrast with the evident growth and aspect shown in non-treated stone probes (Figure 1e,f).

Table 1. Statistical analysis regarding differences in the stone colonization/proliferation area by P. sesnandensis in the absence and in the presence of carrageenan extracts (control vs. treatment).

\begin{tabular}{cc}
\hline Unpaired $t$ Test & Detail \\
\hline$p$ value & 0.0288 \\
$p$ value summary & $*$ \\
Significantly different $(p<0.05) ?$ & Yes \\
$\mathrm{t}, \mathrm{df}$ & $\mathrm{t}=3341, \mathrm{df}=4$ \\
\hline
\end{tabular}

\subsection{SEM and Colorimetric Analyses}

SEM analysis confirmed that $P$. sesnandensis was able to colonize an extensive area in the absence of treatment with carrageenans (Figure $1 \mathrm{i}, \mathrm{j}$ ), while this was largely avoided by the latter (Figure 1k,l). 


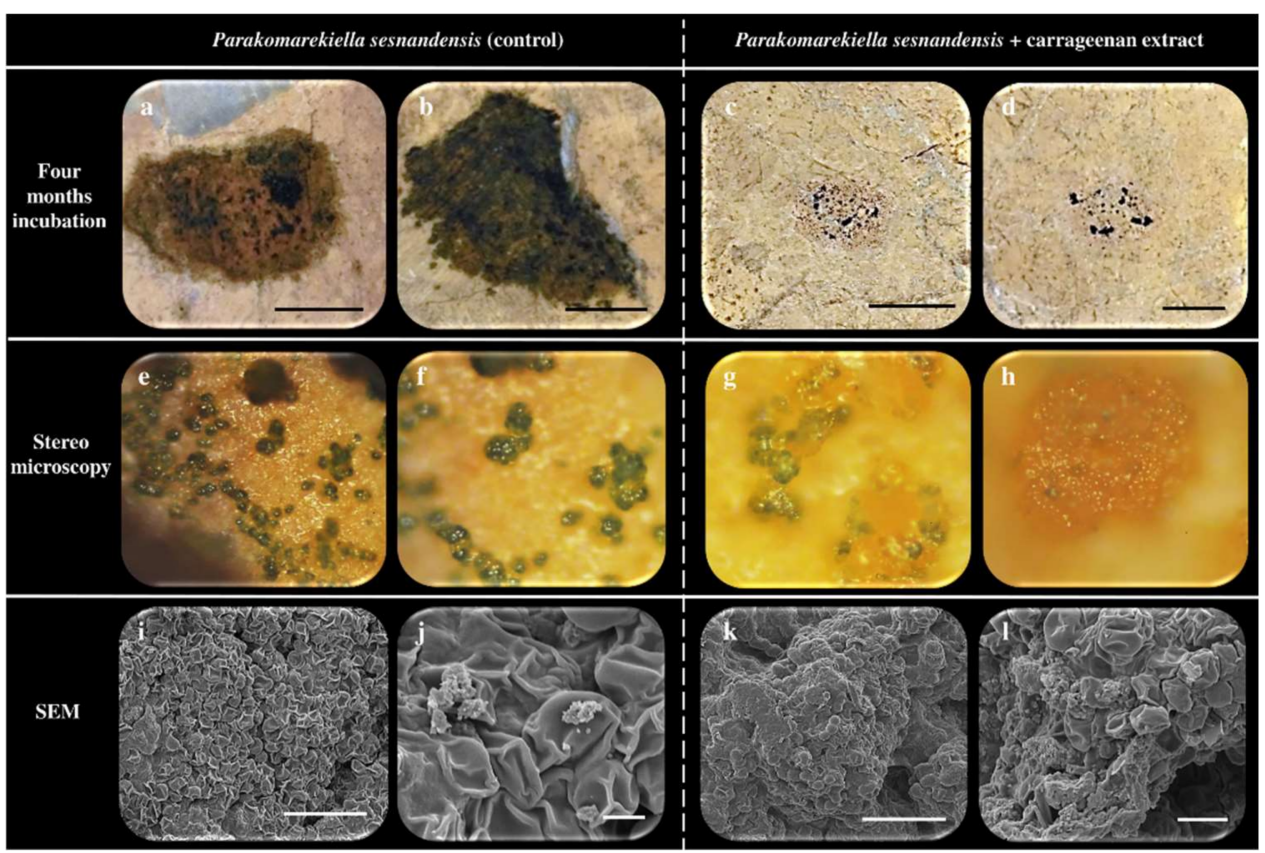

Figure 1. Results regarding visual examination (stereomicroscopy and SEM) of the stone probes inoculated with Parakomarekiella sesnandensis in the absence $(\mathbf{a}, \mathbf{b}, \mathbf{e}, \mathbf{f}, \mathbf{i}, \mathbf{j})$ and in the presence $(\mathbf{c}, \mathbf{d}, \mathbf{g}, \mathbf{h}, \mathbf{k}, \mathbf{l})$ of $200 \mu \mathrm{L}$ of kappa/iota hybrid carrageenans, after 4 months of incubaction. Scale bars: $(\mathbf{a}-\mathbf{d})=1 \mathrm{~cm}$; $(\mathbf{i}, \mathbf{k})=20 \mu \mathrm{m} ;(\mathbf{j})=2 \mu \mathrm{m} ;(\mathbf{l})=5 \mu \mathrm{m}$. Amplification of $(\mathbf{e}-\mathbf{h})=20 \times$.

Colorimetric analysis was performed in order to evaluate chromatic changes on the stone replicas, either caused by experimental conditions (humid vs. dry), the proliferation of $P$. sesnandensis or the application of carrageenans. Samples subjected to P. sesnandensis inoculation without biocide treatment presented $\Delta \mathrm{E}^{*}$ values of 39.57 (Table 2). On the other hand, when treatment was applied, the $\Delta \mathrm{E}^{*}$ values decreased significantly (16.73) and were revealed to be similar to the experimental controls with and without treatment (10.22 and 15.70, respectively) (see Table 2). These large differences reflect the biofilm development, which is clearly enhanced on the non-treated stone replicas. Results from the non-experimental control replicas revealed that the application of the biocide did not cause any significant color variation on stone $\left(\Delta \mathrm{E}^{*}=1.10\right.$; Table 2$)$. The observed changes in $\Delta \mathrm{E}^{*}$ values for the control replicas with treatment under experimental vs. non-experimental conditions result from the different types of environments (humid vs. dry). Thus, under a humid environment (i.e., experimental conditions), the $\Delta \mathrm{E}^{*}$ value of the control stones with carrageenans increases (10.22) but follows a similar pattern verified for the control stones without treatment (15.70) (See Table 2). Complementarily, the graphic analysis for color reflectance (Figure 2) also confirms these assumptions.

Table 2. Colorimetric analysis $(n=3)$ and standard deviation values of the stone replicas subjected to the carrageenan treatment and the growth of $P$. sesnandensis.

\begin{tabular}{lcccc}
\hline & $\mathbf{L}^{*}(\mathbf{D} 65)$ & $\mathbf{a}^{*} \mathbf{( D 6 5 )}$ & $\mathbf{b}^{*}(\mathbf{D 6 5})$ & $\Delta \mathbf{E}^{*}$ \\
\hline Stone Control (Non-experimental) & $70.82( \pm 0.13)$ & $6.36( \pm 0.99)$ & $22.37( \pm 2.26)$ & 0 \\
Biocide on Stone Control (Non-experimental) & $71.50( \pm 1.41)$ & $7.21( \pm 0.19)$ & $22.56( \pm 1.00)$ & 1.10 \\
Stone Control Experimental & $55.93( \pm 0.81)$ & $10.58( \pm 1.69)$ & $24.97( \pm 5.28)$ & 15.70 \\
Biocide on Stone Control Experimental & $62.69( \pm 0.56)$ & $9.15( \pm 1.20)$ & $27.90( \pm 4.49)$ & 10.22 \\
Inoculated Organism on Stone Experimental & $31.72( \pm 8.90)$ & $3.62( \pm 1.61)$ & $16.91( \pm 1.56)$ & 39.57 \\
Inoculated Organism on Stone with Biocide Experimental & $55.34( \pm 6.60)$ & $10.23( \pm 2.83)$ & $27.39( \pm 4.25)$ & 16.73 \\
\hline
\end{tabular}




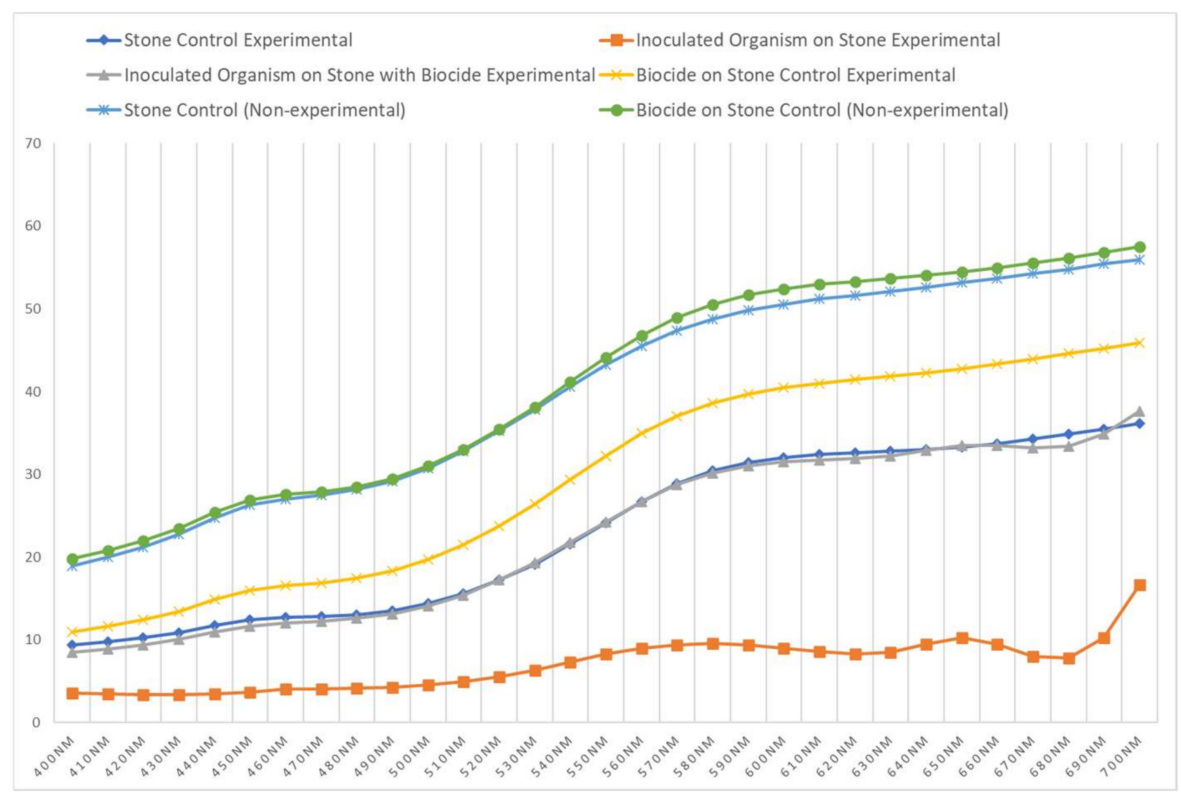

Figure 2. Color reflectance resulting from the biofilm development of $P$. sesnandensis on stone probes with and without carrageenan treatment. Non-experimental designations refer to control probes under dry environment (not subjected to the experimentally controlled humid conditions).

\section{Discussion}

In this study, carrageenans from the female gametophyte life cycle phase of the red seaweed Chondracanthus teedei var. lusitanicus were applied into limestone replicas in order to evaluate their effects on the proliferation of the newly described cyanobacterium Parakomarekiella sesnandensis, under laboratory conditions. Visual effects were inspected after 4 months of treatment application through stereomicroscope and SEM analysis. Color variations were also assessed in order to understand biofilm development and potential chromatic alterations in the stone replicas.

Stone biodeterioration by cyanobacteria is a well-known problem in cultural heritage, as they are potentially one of the most aggressive stone colonizers due to their epilithic and endolithic growth abilities, promoting undesirable aesthetical discolorations as well as physicochemical alterations $[3,36]$. Therefore, there has been an increased necessity to control, or even eliminate, these microorganisms from cultural heritage assets [37]. As it is well documented in the review by Fidanza and Caneva [12], the use of plant- and organism-derived products has been rising in recent years in the field of cultural heritage. However, their study also reflects the almost inexistence exploitation of marine-derived products. In fact, according to the authors, only three marine-derived compounds have been used in this field, among which only one was of marine-algae origin, namely an extract from Ceramium botryocarpum, which was used against phototrophic biofilms dwelling on monumental stone surfaces [38].

In previous studies, carrageenans extracts from the red seaweed Chondracanthus teedei var. lusitanicus were shown to exert antimicrobial properties, namely antifungal and antiviral activities $[18,32]$. The results gathered in the present study highlight the antimicrobial potential of these $C$. teedei var. lusitanicus carrageenans, expanding its usage for preventing the proliferation of $P$. sesnandensis on the surface of the limestones. Overall, this knowledge underlines the potential use of marine-derived extracts on the field of cultural heritage, particularly of sulfated-polysaccharides.

One of the challenges in antimicrobial studies involves understanding the active compound and/or mechanism of action responsible for a given effect. In the study of Cuzman et al. [38], the authors reported that the active compound regarding the seaweed C. botryocarpum extract was still unknown. In our case, the carrageenans extract from 
C. teedei var. lusitanicus is well known and has been previously characterized as a hybrid kappa/iota carrageenans $[18,28]$. Nonetheless, we are still not completely aware of its mode of action against the proliferation of $P$. sesnandensis and, thus, more studies in this regard will be required. Previous studies using the same extracts showed an alteration on the hyphal morphology of two filamentous fungi-Alternaria infectoria and Aspergillus fumigatus [18]. In their study, Soares et al. [18] verified that, upon exposure to $C$. teedei var. lusitanicus carrageenans, the hyphae of $A$. infectoria became swollen, and the hyphae of $A$. fumigatus became shortened and highly branched, which are phenotypic characteristics commonly triggered in response to antifungals $[18,39,40]$. In addition, these morphological alterations were also associated with variations on the cell wall components of these fungi, namely in their $\beta$-glucan and chitin content [18]. Although we did not observe any morphological change in the filaments of $P$. sesnandensis, we could still notice that upon carrageenans treatment, some cells became yellow, a feature commonly observed in laboratory, when the cultures of $P$. sesnandensis need to be transferred to a new and fresh culture medium. Although additional studies are needed, this could potentially indicate that cell viability might be compromised upon exposure to these extracts.

In our study, we were able to verify that the lithotype used was bioreceptive to the colonization and growth of the cyanobacterium P. sesnandensis, showing that even single species are able to successfully colonize stone surfaces. Visual inspection in the probes without treatment also demonstrated the capacity of P. sesnandensis to grow epilithically, leading to undesirable aesthetic alterations due to its intense dark-green color.

In regard to the colorimetric analysis, results showed that the application of carrageenans did not cause any color alteration to the surface of the stone in control replicas under dry environment (non-experimental). The $\Delta \mathrm{E}^{*}$ value upon exposure to treatment was 1.10, similar to the reference value for stone replicas (Table 1). However, in control replicas under a humid environment, $\Delta \mathrm{E}^{*}$ values in stone probes (in the presence or absence of carrageenans treatment) were greater than 1 . According to literature data, stone treatments should not cause $\Delta \mathrm{E}^{*}$ variations greater than 4 or 5 [41-43]. We hypothesize that these differences resulted from the presence of water in the experimental conditions. Nonetheless, both $\Delta \mathrm{E}^{*}$ values for non-experimental control probes with and without carrageenans were revealed to be similar, as expected. Other studies in this field have shown some color alterations on stone replicas after application of natural compounds (e.g., [11]). Colorimetric analysis is an important and reliable non-destructive method used in the cultural heritage field for monitoring biofilm growth on stone surfaces [44,45]. In this regard, our results demonstrated that biofilm formation was enhanced in non-treated stone replicas as compared to carrageenans-treated samples, highlighting their effectiveness in controlling the proliferation of P. sesnandensis.

It is important to note that, ideally, biocides and other compounds should be tested on the same material as the studied monument, possibly colonized with the same naturally developed microbial community, in order to mimic real case scenarios [10,46]. In addition, their possible interactions on the tested material should also be evaluated prior to application in situ, to avoid any negative effects to the stone surfaces [43]. Our experiments followed these guidelines, as we use stone replicas similar to the ones used in the construction of the Old Cathedral of Coimbra. Although the results presented here were evaluated on a short-term basis (after 4 months of incubation), they suggest that one sole application of the carrageenans extract may be sufficient to retard the proliferation of $P$. sesnandensis. In fact, preliminary results performed with one replicate for a period of 1 year without any additional biocide application showed that this effect persists (Supplementary Figure S1), which consolidates our theory that these compounds do not require frequent periodic applications to control these organisms. In addition, and even though these extracts were only tested in one organism, we hypothesize that they could also be used as a complement after cleaning, to help in retarding the growth of some microorganisms. Nevertheless, we are aware that the practical use of carrageenans in cultural heritage scenarios would still need further studies and procedures, as the European Biocidal Product Regulation 
(Regulation 528/2012) implies that the active substances used in biocidal products must undergo legal approval by the European Chemicals Agency (ECHA) before they can be put on the market, to ensure a high level of protection for human health and the environment. Although carrageenans are generally regarded as safe and are used in a variety of industrial fields (e.g., food, cosmetics, pharmaceutical, etc.), to the best of our knowledge, they are still not included in the list of existing substances approved by ECHA, which can be a limitation for their use in the field of cultural heritage in the coming years. Furthermore, although the legislation in Europe and in the USA is largely similar, some countries still regulate the use of biocides by their own national authorities [43], having consequences to the use of biocides applied on cultural heritage [43]. For example, although sodium azide is used to treat fungal biofilms on marble monuments in Cairo, Egypt [43,47], this substance can have an impact on human health [43]. Therefore, we understand that, although limitations can be posed to the use of biocides in the field of cultural heritage, continuous studies must be undertaken to ensure the protection of humans and the environment.

\section{Conclusions}

The present work allowed us to observe that, under carrageenans treatment, the proliferation of $P$. sesnandensis could be retarded. This study also highlights the potential use of marine-derived extracts on the field of cultural heritage, particularly of sulfatedpolysaccharides, as alternative methods for biocleaning cultural heritage assets.

Supplementary Materials: The following are available online at https:/ / www.mdpi.com/article/10 .3390/app112210589/s1, Figure S1: Preliminary results regarding one stone probe replicate inoculated with Parakomarekiella sesnandensis in the absence (a) and in the presence (b) of $200 \mu \mathrm{L}$ of kappa/iota hybrid carrageenans, after 1 year incubation period.

Author Contributions: Conceptualization, F.S.; methodology, F.S.; software, F.S., J.T., L.C. and F.G.; formal analysis, F.S. and J.T.; writing — original draft preparation, F.S.; writing — review and editing, F.S., J.T., F.G., L.C., I.T, A.P. and S.M.C.; supervision, A.P., I.T. and S.M.C.; funding acquisition, A.P. All authors have read and agreed to the published version of the manuscript.

Funding: This research was financed by FEDER- Fundo Europeu de Desenvolvimento Regional funds through the COMPETE 2020-Operational Programme for Competitiveness and Internationalisation (POCI) and by Portuguese funds through FCT-Fundação para a Ciência e a Tecnologia in the framework of the project POCI-01-0145-FEDERPTDC/EPH-PAT/3345/2014. This work was also financed by IPN-Financiamento Base FITEC approved under the National Call with reference no. 01/FITEC/2018 to obtain multi-year base financing under the INTERFACE Program. This work was conducted at the R\&D Unit Centre for Functional Ecology-Science for People \& the Planet (CFE) with reference UIDB/04004/2020, financed by FCT/MCTES through national funds (PIDDAC). Fabiana Soares was supported by $\mathrm{POCH}$-Programa Operacional Capital Humano (co-funding by the European Social Fund and national funding by MCTES), through a "FCT—Fundação para a Ciência e Tecnologia" PhD research grant (SFRH/BD/139720/2018). João Trovão was supported by POCHPrograma Operacional Capital Humano (co-funding by the European Social Fund and national funding by MCTES), through a "FCT—Fundação para a Ciência e Tecnologia" PhD research grant (SFRH/BD/132523/2017). Igor Tiago acknowledges an Investigator contract reference IF/01061/2014. We gratefully acknowledge TAIL-UC, funded under QREN-Mais Centro Project ICT-2009-02-012-1980. The financial support of FCT through national funds and the research project UIDB/00073/2020 of the Geosciences Center is also acknowledged. Thanks to the Univ Aveiro and FCT/MEC for funding the associated laboratory LAQV-REQUIMTE (project reference UIDB/50006/2020), through national funds and co-financed by Fundo Europeu de Desenvolvimento Regional (FEDER), within the PT2020 Partnership Agreement. SMC thanks the Research contract through project PTDC/BAAAGR/31015/2017 (Algaphlor).

Institutional Review Board Statement: Not applicable.

Informed Consent Statement: Not applicable.

Data Availability Statement: Not applicable. 
Acknowledgments: The authors would like to thank Leonel Pereira for kindly providing the room to carry out this experiment.

Conflicts of Interest: The authors declare no conflict of interest.

\section{References}

1. Hoffmann, L. Algae of terrestrial habitats. Bot. Rev. 1989, 55, 77-105. [CrossRef]

2. Crispim, C.A.; Gaylarde, C.C. Cyanobacteria and biodeterioration of cultural heritage: A review. Microb. Ecol. 2005, 49, 1-9. [CrossRef] [PubMed]

3. Macedo, M.F.; Miller, A.Z.; Dionísio, A.; Saiz-Jimenez, C. Biodiversity of cyanobacteria and green algae on monuments in the Mediterranean Basin: An overview. Microbiology 2009, 155, 3476-3490. [CrossRef]

4. Gaylarde, C.C. Influence of Environment on Microbial Colonization of Historic Stone Buildings with Emphasis on Cyanobacteria. Heritage 2020, 3, 1469-1482. [CrossRef]

5. Rossi, F.; Micheletti, E.; Bruno, L.; Adhikary, S.P.; Albertano, P.; Phillips, R.D. Characteristics and role of the exocellular polysaccharides produced by five cyanobacteria isolated from phototrophic biofilms growing on stone monuments. Biofouling 2012, 28, 215-224. [CrossRef]

6. De Los Ríos, A.; Galván, V.; Ascaso, C. In situ microscopical diagnosis of biodeterioration processes at the convent of Santa Cruz la Real, Segovia, Spain. Int. Biodeterior. Biodegrad. 2004, 54, 113-120. [CrossRef]

7. Dakal, T.C.; Cameotra, S.S. Microbially induced deterioration of architectural heritages: Routes and mechanisms involved Environ. Sci. Eur. 2012, 24,1-13. [CrossRef]

8. Soares, F.; Portugal, A.; Trovão, J.; Coelho, C.; Mesquita, N.; Pinheiro, A.C.; Gil, F.; Catarino, L.; Cardoso, S.M.; Tiago, I. Structural diversity of photoautotrophic populations within the UNESCO site 'Old Cathedral of Coimbra' (Portugal), using a combined approach. Int. Biodeterior. Biodegrad. 2019, 140, 9-20. [CrossRef]

9. Soares, F.; Trovão, J.; Cardoso, S.M.; Tiago, I.; Portugal, A. Parakomarekiella sesnandensis gen. et sp. nov. (Nostocales, Cyanobacteria) isolated from the Old Cathedral of Coimbra, Portugal (UNESCO World Heritage Site). Eur. J. Phycol. 2020, 56, 301-315. [CrossRef]

10. Tiano, P. Biodeterioration of monumental rocks: Decay mechanisms and control methods. Sci. Technol. Cult. Herit. 1998, 7, 19-38.

11. Sasso, S.; Miller, A.Z.; Rogerio-Candelera, M.A.; Cubero, B.; Coutinho, M.L.; Scrano, L.; Bufo, S.A. Potential of natural biocides for biocontrolling phototrophic colonization on limestone. Int. Biodeterior. Biodegrad. 2015, 107, 102-110. [CrossRef]

12. Fidanza, M.R.; Caneva, G. Natural biocides for the conservation of stone cultural heritage: A review. J. Cult. Herit. 2019, 38, 271-286. [CrossRef]

13. De Saravia, S.G.; Rastelli, S.E.; Blustein, G.; Viera, M.R. Natural compounds as potential algaecides for waterborne paints. J. Coat. Technol. Res. 2018, 15, 1191-1200. [CrossRef]

14. Bruno, L.; Rugnini, L.; Spizzichino, V.; Caneve, L.; Canini, A.; Ellwood, N.T.W. Biodeterioration of Roman hypogea: The case study of the Catacombs of SS. Marcellino and Pietro (Rome, Italy). Ann. Microbiol. 2019, 69, 1023-1032. [CrossRef]

15. Stanley, N.F. Production, properties and use of carrageenans. In Production and Utilization of Products from Commercial Seaweeds; McHugh, D.J., Ed.; Food and Agriculture Organization of the United Nations: Rome, Italy, 1987; pp. 97-147.

16. Yuan, H.; Song, J.; Li, X.; Li, N.; Liu, S. Enhanced immunostimulatory and antitumor activity of different derivatives of K-carrageenan oligosaccharides from Kappaphycus striatum. J. Appl. Phycol. 2010, 23, 59-65. [CrossRef]

17. Patel, S. Therapeutic importance of sulfated polysaccharides from seaweeds: Updating the recent findings. Biotech 2012, 3 , 171-185. [CrossRef]

18. Soares, F.; Fernandes, C.; Silva, P.; Pereira, L.; Gonçalves, T. Antifungal activity of carrageenan extracts from the red alga Chondracanthus teedei var. lusitanicus. J. Appl. Phycol. 2016, 5, 2991-2998. [CrossRef]

19. Perez, R.; Kaas, R.; Campello, F.; Arbault, S.; Baarbaroux, O. La Culture des Algues Marines dans le Monde; IFREMER: Plouzané, France, $1992 ;$ p. 637.

20. Cardoso, S.M.; Carvalho, L.G.; Silva, P.J.; Rodrigues, M.S.; Pereira, O.R.; Pereira, L. Bioproducts from macroalgae: A review with focus on the Iberian Peninsula. Curr. Org. Chem. 2014, 18, 896-917. [CrossRef]

21. Jiao, G.; Yu, G.; Zhang, J.; Ewart, H.S. Chemical structures and bioactivities of sulfated polysaccharides from marine algae. Mar. Drugs 2011, 9, 196-223. [CrossRef]

22. Rudolph, B. Seaweed products: Red algae of economic significance. In Marine E Freshwater Products Handbook; Martin, R.E., Ed.; Technomic Pub Co.: Lancaster, UK, 2000; pp. 515-529.

23. Pereira, L.; Van de Velde, F. Portuguese carrageenophytes: Carrageenans composition and geographic distribution of eight species (Gigartinales, Rhodophyta). Carbohydr. Polym. 2011, 84, 614-623. [CrossRef]

24. Guiry, M.D. Structure, life-history and hybridization of Atlantic Gigartina teedii (Rhodophyta) in culture. Brit. Phycol. J. 1984, 19, 37-55. [CrossRef]

25. Braga, M.R.A. Taxonomia e Biologia da Gigartina Teedii (Roth) Lamouroux (Rhodophyta, Gigartinales) no Litoral do Estado de São Paulo. Ph.D. Thesis, University São Paulo, São Paulo, Brazil, 1985.

26. Braga, M.R.A. Reproductive characteristics of Gigartina teedii (Roth) Lamouroux (Rhodophyta, Gigartinales), a turf-forming species-Field and laboratory culture studies. Bot. Mar. 1990, 33, 401-409.

27. Pereira, L.; Gheda, S.F.; Ribeiro-Claro, P.J.A. Analysis by vibrational spectroscopy of seaweed polysaccharides with potential use in food, pharmaceutical, and cosmetic industries. Int. J. Carbohydr. Chem. 2013, 2013, 537202. [CrossRef] 
28. Pereira, L.; Mesquita, J.F. Population studies and carrageenan properties of Chondracanthus teedei var. lusitanicus (Gigartinaceae, Rhodophyta). J. Appl. Phycol. 2004, 16, 369-383. [CrossRef]

29. Gaspar, R.; Pereira, L.; Sousa-Pinto, I. The seaweed resources of Portugal. Bot. Mar. 2019, 62, 499-525. [CrossRef]

30. Pereira, L.; Silva, P. A concise review of the red macroalgae Chondracanthus teedei (Mertens ex Roth) Kützing and Chondracanthus teedei var. lusitanicus (J.E. De Mesquita Rodrigues) Bárbara \& Cremades. J. Appl. Phycol. 2020, 33, 111-131.

31. Pereira, L.; Amado, A.M.; Critchley, A.T.; van de Velde, F.; Ribeiro-Claro, P.J.A. Identification of selected seaweed polysaccharides (phycocolloids) by vibrational spectroscopy (FTIR-ATR and FTRaman). Food Hydrocoll. 2009, 23, 1903-1909. [CrossRef]

32. Soares, F. Antifungal, Antibacterial and Antiviral Activity of Chondracathus Teedei var. Lusitanicus (Gigartinaceae, Rhodophyta). Master's Thesis, University of Coimbra, Coimbra, Portugal, 2015.

33. Zinoun, M.; Cosson, J. Seasonal variation in growth and carrageenan content of Calliblepharis jubata (Rhodophyceae, Gigartinales) from the Normandy coast, France. J. Appl. Phycol. 1996, 8, 29-34. [CrossRef]

34. Huertas, R.; Melgosa, M.; Hita, E. Influence of random-dot textures on perception of suprathreshold color differences. J. Opt. Soc. Am. A 2006, 23, 2067-2076. [CrossRef] [PubMed]

35. Prieto, B.; Vázquez-Nion, D.; Fuentes, E.; Durán-Román, A.G. Response of subaerial biofilms growing on stone-built cultural heritage to changing water regime and $\mathrm{CO}_{2}$ conditions. Int. Biodeterior. Biodegrad. 2020, 148, 104882. [CrossRef]

36. Tomaselli, L.; Lamenti, G.; Bosco, M.; Tiano, P. Biodiversity of photosynthetic micro-organisms dwelling on stone monuments. Int. Biodeterior. Biodegrad. 2000, 46, 251-258. [CrossRef]

37. Coutinho, M.L.; Miller, A.Z.; Martin-Sanchez, P.M.; Mirão, J.; Gomez-Bolea, A.; Machado-Moreira, B.; Cerqueira-Alvesi, L.; Jurado, V.; Saiz-Jimenez, C.; Lima, A.; et al. A multi-proxy approach to evaluate biocidal treatments on biodeteriorated majolica glazed tiles. Environ. Microbiol. 2016, 18, 4794-4816. [CrossRef] [PubMed]

38. Cuzman, O.A.; Camaiti, M.; Sacchi, B.; Tiano, P. Natural antibiofouling agents asnew control method for phototrophic biofilms dwelling on monumental stone surfaces. Int. J. Conserv. Sci. 2011, 2, 3-16.

39. Verwer, P.E.B.; van Duijn, M.L.; Tavakol, M.; Bakker-Woudenberg, I.A.J.M.; van de Sande, W.W.J. Reshuffling of Aspergillus fumigatus cell wall components chitin and $\beta$-glucan under the influence of caspofungin or nikkomycin $\mathrm{Z}$ alone or in combination. Antimicrob. Agents Chemother. 2012, 56, 1595-1598. [CrossRef]

40. Fernandes, C.; Anjos, J.; Walker, L.A.; Silva, B.M.; Cortes, L.; Mota, M.; Munro, C.A.; Gow, N.A.; Gonçalves, T. Modulation of Alternaria infectoria cell wall chitin and glucan synthesis by cell wall synthase inhibitors. Antimicrob. Agents Chemother. 2014, 58, 2894-2904. [CrossRef] [PubMed]

41. Sasse, H.S.; Snethlage, R. Methods for the Evaluation of Stone Conservation Treatments. In Dahlem Workshop on Saving Our Architectural Heritage; Baer, N.S., Snethlage, R., Eds.; John Wiley \& Sons Ltd.: Berlin, Germany, 1996.

42. Vigliano, G. Graffiti and Antigraffiti Project. 2002. Available online: http:/ / www.icr.beniculturali.it/ (accessed on 2 November 2021).

43. Pinna, D. Coping with Biological Growth on Stone Heritage Objects: Methods, Products, Applications, and Perspectives; Apple Academic Press: Waretown, DC, USA, 2017; 382p.

44. Prieto, B.; Silva, B.; Lantes, O. Biofilm quantification on stone surfaces: Comparison of various methods. Sci. Total Environ. 2004, 333, 1-7. [CrossRef]

45. Sanmartín, P.; Vázquez-Nion, D.; Silva, B.; Prieto, B. Spectrophotometric color measurement for early detection and monitoring of greening on granite buildings. Biofouling 2012, 28, 329-338. [CrossRef]

46. Allsopp, C.; Allsopp, D. An updated survey of commercial products used to protect materials against biodeterioration. Biodet. Bull. 1983, 19, 99-146. [CrossRef]

47. Abdelhafez, A.A.M.; El-Wekeek, F.M.; Ramadan, E.M.; Abed-Allah, A.A. Microbial deterioration of archaeological marble: Identification and treatment. Ann. Agric. Sci. 2012, 57, 137-144. [CrossRef] 